\title{
Structural and magnetic characterization of plasma ion nitrided layer on 316L stainless steel alloy
}

\author{
O. Öztürk ${ }^{\mathrm{a}, *}$, S. Okur ${ }^{\mathrm{a}}$, J.P. Riviere ${ }^{\mathrm{b}}$ \\ a Department of Physics, Izmir Institute of Technology, Gulbahce-Urla, Izmir 35430, Turkey \\ ${ }^{\mathrm{b}}$ Laboratoire de Metallurgie Physique, University of Poitiers, Poitiers 86960, France
}

\section{A R T I C L E I N F O}

Article history:

Available online 30 January 2009

\section{PACS:}

81.65.Lp

07.55.Jg

81.05.Bx

61.05. $-\mathrm{a}$

\section{Keywords:}

Plasma nitriding

Magnetic force microscopy

Stainless steel

VSM

XRD

\begin{abstract}
A B S T R A C T
In this study, an FeCrNi alloy (316L stainless steel disc) was nitrided in a low-pressure R.F. plasma at $430{ }^{\circ} \mathrm{C}$ for $72 \mathrm{~min}$ under a gas mixture of $60 \% \mathrm{~N}_{2}-40 \% \mathrm{H}_{2}$. Structural, compositional and magnetic properties of the plasma nitrided layer was investigated by X-ray diffraction (XRD), scanning electron microscopy (SEM), atomic force microscopy (AFM) and magnetic force microscopy (MFM). The magnetic behaviour of the nitrided layer was also investigated with a vibrating sample magnetometer (VSM). Combined X-ray diffraction, cross-sectional SEM, AFM and MFM, as well as VSM analyses provide strong evidence for the formation of the $\gamma_{\mathrm{N}}$ phase, $\left[\gamma_{\mathrm{N}}-(\mathrm{Fe}, \mathrm{Cr}, \mathrm{Ni})\right]$, with mainly ferromagnetic characteristics. The uniform nature of the $\gamma_{\mathrm{N}}$ layer is clearly demonstrated by the XRD, cross-sectional SEM and AFM analyses. Based on the AFM and SEM data, the thickness of the $\gamma_{N}$ layer is found to be $\sim 6 \mu \mathrm{m}$. According to the MFM and VSM analyses, ferromagnetism in the $\gamma_{\mathrm{N}}$ layer is revealed by the observation of stripe domain structures and the hysteresis loops. The cross-sectional MFM results demonstrate the ferromagnetic $\gamma_{\mathrm{N}}$ phase distributed across the plasma nitrided layer. The MFM images show variation in the size and form of the magnetic domains from one grain to another.
\end{abstract}

(C) 2009 Elsevier B.V. All rights reserved.

\section{Introduction}

It is well-established that nitrogen incorporation into the surface of austenitic stainless steel alloys (304,310,316 SS) by a wide variety of surface modification techniques at a relatively low surface treatment temperature of $\sim 400{ }^{\circ} \mathrm{C}$ leads to a high- $\mathrm{N}$ phase, $\gamma_{N}$, in the treated layers [1-8]. High strength (hardness values as high as $20 \mathrm{GPa}$ ), good corrosion resistance and dramatically improved wear resistance under high loads are a few of the technologically important properties reported in the literature for the $\gamma_{N}$ phase [3]. Another unusual property of the $\gamma_{N}$ phase is related to its magnetic nature. Depending on its $\mathrm{N}$ contents and associated lattice expansions, this phase is found to have ferromagnetic as well as paramagnetic characteristics [3,9]. Clearly, having a magnetic layer $\left(\gamma_{\mathrm{N}}\right)$ on non-magnetic substrate (underlying fcc $\gamma$ phase of austenitic stainless steel has paramagnetic characteristics) in addition to its high strength and good corrosion resistance may have industrial applications similar to those of iron nitrides which are potential candidates in high density magnetic recording applications.

Although the $\gamma_{\mathrm{N}}$ phase has been extensively investigated by various research groups, studies related to its magnetic character have been lacking. One of the first studies reporting ferromagnetic

\footnotetext{
* Corresponding author. Tel.: +90 232750 7708; fax: +90 2327507707 .

E-mail address: orhanozturk@iyte.edu.tr (O. Öztürk).
}

behaviour for the $\gamma_{\mathrm{N}}$ phase was a nitriding study of $304 \mathrm{SS}$ at $400{ }^{\circ} \mathrm{C}$ [1]. A much later study [9] involving low-energy, high-flux $\mathrm{N}$ implantation of $304 \mathrm{SS}$ at $400{ }^{\circ} \mathrm{C}$ revealed many more details about the magnetic nature of the $\gamma_{\mathrm{N}}$ phase. This study (via Mössbauer spectroscopy) found that the $\gamma_{\mathrm{N}}$ phase had the magnetic properties of a soft magnetic material and was distributed in the highest $\mathrm{N}$ concentration (and associated lattice expansion) region of the implanted layer. Furthermore, this study revealed that the $\gamma_{\mathrm{N}}$ phase transformed to the paramagnetic state deeper into the layer as the $\mathrm{N}$ content and lattice expansion decreased. More recently, the magnetic nature of the $\gamma_{\mathrm{N}}$ phase has been investigated by magnetic force microscopy (MFM) analyses $[10,11]$. The MFM analysis of a low-energy $(700 \mathrm{eV})$, high-flux $\left(2.0 \mathrm{~mA} / \mathrm{cm}^{2}\right)$ nitrogen implanted $316 \mathrm{SS}$ sample at a substrate temperature of $410^{\circ} \mathrm{C}$ showed ferromagnetic maze-like, thin-film domain structures. This study [10] also found out that the magnetic behaviour varied significantly from one grain to another. This variation was explained by the non-uniform $\mathrm{N}$ contents and different amounts of lattice expansion in the different grains. Another MFM study [11] performed on a cross-section of a 316 SS sample treated by plasmaimmersion ion implantation at a substrate temperature of $400^{\circ} \mathrm{C}$ showed that the magnetic domains extend for only approximately $80 \%$ of the thickness of the nitrogen-rich layer (the deepest $20 \%$ of the $\gamma_{\mathrm{N}}$ layer was assumed to be paramagnetic). Mössbauer analyses in $[9,10]$ suggest that volume dependence of the magnetic properties of fcc-Fe is behind the ferromagnetic behaviour for the 
$\gamma_{\mathrm{N}}$ and that the magnetism of $\gamma_{\mathrm{N}}$ phase is likely related to the ferromagnetic state of $\gamma^{\prime}-\mathrm{Fe}_{4} \mathrm{~N}$.

The focus of this study is to investigate the structural and magnetic properties of the $\gamma_{\mathrm{N}}$ phase in much more detail. The formation of the $\gamma_{\mathrm{N}}$ layer is accomplished through low-pressure R.F. plasma nitriding of 316L stainless steel at a substrate temperature of $430{ }^{\circ} \mathrm{C}$. Structural and compositional properties of the $\gamma_{\mathrm{N}}$ layer will be analysed by XRD, cross-sectional SEM, EDX and AFM. The magnetic behaviour of the $\gamma_{\mathrm{N}}$ layer will be mainly investigated by magnetic force microscopy (MFM) and vibrating sample magnetometry (VSM).

\section{Experimental details}

Austenitic fcc 316L stainless steel with elemental compositions of $19 \% \mathrm{Cr}, 14 \% \mathrm{Ni}, 2 \% \mathrm{Mo}, 2 \% \mathrm{Mn}, 1 \% \mathrm{Si}, 0.1 \% \mathrm{C}$ and balance Fe (all in at.\%), was the base material to which plasma nitriding was applied. The 316L SS specimen had a disc-like geometry with a diameter of $1.0 \mathrm{~cm}$ and a thickness of $0.30 \mathrm{~cm}$. Before nitriding, the specimen was polished to mirror-like quality with a mean surface roughness of about $\sim 0.01 \mu \mathrm{m}$ (based on surface profilometry), and then was degreased with acetone, rinsed with alcohol in an ultrasonic bath, and finally dried. The nitriding was carried out in a specific plasma reactor allowing high rate nitriding at low temperature without any sputtering of the sample surface. The plasma in this reactor is generated in a quartz tube by R.F. excitation $(13.56 \mathrm{MHz})$ of a low-pressure gas mixture. The RF excitation of the plasma produces a surface wave to maintain the plasma properties constant along the tube. The details about the plasma reactor used in this study can be found elsewhere [12]. In this study, the 316L SS sample was exposed to the following plasma nitriding conditions: (1) gas composition of $60 \% \mathrm{~N}_{2}+40 \% \mathrm{H}_{2}$, (2) working pressure of $7.5 \mathrm{~Pa}$, (3) RF power of $700 \mathrm{~W}$, (4) the substrate temperature of $430{ }^{\circ} \mathrm{C}$ and (5) nitriding duration of $72 \mathrm{~min}$. In the plasma method applied here, the mean energy of the accelerated ions is $15 \mathrm{eV}$, which is lower than the sputtering threshold for the majority of materials. The nitriding conditions implemented in this study were determined from previous research on 304 SS [13].

Near-surface crystal structures of the plasma nitrided 316L SS specimen were analysed by symmetric $\theta / 2 \theta$ (Bragg-Brentano) diffractometer (Philips X'pert) with $\mathrm{Cu}-\mathrm{K} \alpha$ radiation. The XRD data for the nitrided sample were analysed to estimate an average nitrogen concentration for the nitrided layer. The $\mathrm{N}$ content for the nitrided layer was also determined by energy dispersive X-rays (EDX). The nitrided layer thickness was determined by cross-sectional scanning electron microscopy and atomic force microscopy. For the thickness analysis, a cross-section of the nitrided specimen was prepared by means of polishing and chemical etching (Marble's solution). The magnetic behaviour of the plasma nitrided surface was investigated with a scanning probe microscope in magnetic force mode (MFM). In the MFM technique, a probe tip coated with a magnetic material gives an image showing the variation in the magnetic force between the magnetized probe and remnant magnetic domains in the sample surface [14]. The MFM analysis was also carried out on the cross-section of the nitrided sample to determine the magnetic phase distribution across the nitrided layer. Hysteresis loops were obtained by a vibrating sample magnetometer (VSM) to probe further the magnetic characteristics of the nitrided layer.

\section{Results and discussion}

The XRD results for the as-polished substrate and RF plasma nitrided 316L SS specimens are shown in Fig. 1. In this figure, the fcc substrate peaks are labeled as $\gamma(h k l)$ and the plasma nitriding in-

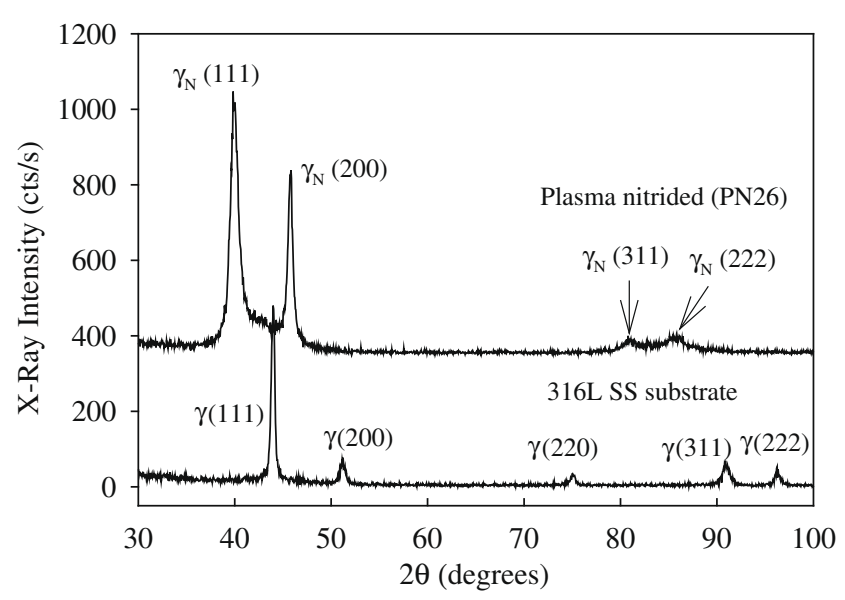

Fig. 1. XRD data for the plasma nitrided 316L specimen (PN26 is sample name). Also presented in this figure are the XRD data for the 316L SS substrate alloy.

duced ones as $\gamma_{\mathrm{N}}(h k l)$. The results clearly indicate that the plasma nitrided layer is composed of the high-N content phase $\gamma_{N}$. The $\gamma_{N}$ formation is consistent with previous studies, where it was almost always observed when the substrate temperature was held near $400{ }^{\circ} \mathrm{C}[3,9,10]$. The XRD results for the nitrided sample are consistent with those of other low-pressure plasma nitrided and low-energy, high-flux $N$ implanted SS samples, in that the $\gamma_{N}(200)$ peak is shifted more than the $\gamma_{\mathrm{N}}(111)$ relative to the substrate peaks $[15,16]$. Based on Vegard's law, these results suggest larger $N$ contents in the (200) oriented grains (see Table 1 for details). The absence of the substrate peaks in the XRD data of the nitrided specimen suggests quite a thick nitrided layer. The narrow and symmetric nature of the $\gamma_{\mathrm{N}}$ peaks in Fig. 1 suggest a uniform nitrogen distribution in the nitrided layer.

The XRD data in Fig. 1 were analysed quantitatively to extract lattice constant values for the nitrided as well as the substrate specimens. The results are presented in Table 1. From the values in Table 1, and based on the quantitative XRD analysis method and Vegard's law (see [9] and references therein), an average $\mathrm{N}$ content for the plasma nitrided layer was estimated and found to be about 42 at.\%. However, this value is believed to be overestimated since the quantitative analysis method did not take into account the compressive residual stresses that may be present in the $\gamma_{\mathrm{N}}$ layer. As can be seen from Table 1 , the $\gamma_{\mathrm{N}}$ lattice expansion compared to the substrate fcc $\gamma-(\mathrm{Fe}, \mathrm{Cr}, \mathrm{Ni})$ phase is about $10 \%$ and such values are quite likely to induce compressive stresses in the nitrided layer [9]. Also, the use of Vegard's law in estimating an aver-

\section{Table 1}

Lattice parameters, $d$ and $a$, in $\AA$ for the 316L SS fcc $\gamma$ substrate phase and the fcc $\gamma_{\mathrm{N}}$ phase. $\Delta a / a$ refers to the relative difference in lattice spacing and is given by $\Delta a /$ $a=\left[\left\{a\left(\gamma_{\mathrm{N}}\right)-a(\gamma)\right\} / a(\gamma)\right]$. Based on the values in this table and [9], an average $\mathrm{N}$ content for the $\gamma_{N}$ layer is found be $\sim 42$ at.\%. In estimating an average $N$ content for the nitrided layer, Vegard's law is used (see [9] and references therein). The use of Vegard's law in estimating an average $\mathrm{N}$ content for the nitrided layer based on the XRD data may be questionable, since it is probably not appropriate to extrapolate to high concentration based on a linear correlation between lattice parameter and atomic concentration.

\begin{tabular}{llllllc}
\hline$h k l)$ & \multicolumn{2}{l}{$316 \mathrm{~L}$ substrate } & & \multicolumn{2}{l}{ Plasma nitrided } & \multirow{2}{*}{$\Delta a / a(\%)$} \\
\cline { 2 - 3 } & $d(\gamma)$ & $a(\gamma)$ & & $d\left(\gamma_{\mathrm{N}}\right)$ & $a\left(\gamma_{\mathrm{N}}\right)$ & \\
\hline$(111)$ & 2.057 & 3.563 & & 2.253 & 3.902 & 9.5 \\
$(200)$ & 1.783 & 3.565 & & 1.981 & 3.962 & 11.1 \\
$(220)$ & 1.264 & 3.575 & & - & - & - \\
$(311)$ & 1.080 & 3.582 & & 1.185 & 3.930 & 9.7 \\
$(222)$ & 1.034 & 3.582 & & 1.133 & 3.925 & 9.6 \\
Average & - & 3.573 & & - & 3.929 & $\sim 10$ \\
\hline
\end{tabular}


age $\mathrm{N}$ content for the nitrided layer based on the XRD data may be questionable, since it is probably not appropriate to extrapolate to high concentration based on a linear correlation between lattice parameter and atomic concentration.

The nitrogen concentration for the plasma nitrided layer was also determined by energy dispersive X-rays (EDX). The experimental results indicate that the $\mathrm{N}$ content of the $\gamma_{\mathrm{N}}$ layer is about 35 at.\%. The EDX data were analysed through a modern 'Quantitative Standardless Analysis' Package. Although the analysis through this package offers an accurate representation of the composition of the material, the guidelines provided suggest, for example, an error of up to $10 \%$ for the concentration range of 5-20 wt.\% (the error increases as the range decreases). So, the average $\mathrm{N}$ content based on the EDX analysis in this study is 35 at.\% ( $12 \mathrm{wt} . \%$ ), and this is accurate within $\pm 10 \%$. We think that this EDX value may also be overestimated and believe that the average $\mathrm{N}$ content for the nitrided layer is actually lower. In an earlier study of a lowenergy $(700 \mathrm{eV})$, high-flux $\mathrm{N}$ implantation of $316 \mathrm{SS}$ at about $410^{\circ} \mathrm{C}$ for $1 \mathrm{~h}$, composition of the near surface region was measured by glow discharge optical emission spectroscopy (GDOES). This study [10] found that the maximum $\mathrm{N}$ content near the surface obtained from the GDOES profile for the N implanted sample was 32 at.\%. The XRD data for the $\mathrm{N}$ implanted sample in Williamson et al. [10] looks quite similar to the nitrided sample in our study in that the substrate peaks are also absent in the XRD data (indicating a thick $\mathrm{N}$ implanted layer, about $6 \mu \mathrm{m}$ according to the GDOES results). Also, the lattice constants associated with the (111) and (200) $\gamma_{\mathrm{N}}$ reflections for the $\mathrm{N}$ implanted sample are nearly identical to the ones in this study suggesting similar lattice expansions for the $\mathrm{N}$ implanted and nitrided samples. A much earlier concentration analysis study [9] based on electron probe microanalysis (EPMA) of another low-energy (1 keV), high-flux $\mathrm{N}$ implanted 304 SS (similar in composition to 316 SS) found that the average $\mathrm{N}$ content in the top $1 \mu \mathrm{m}$ of the $\mathrm{N}$ implanted layer (the approximate EPMA probe depth) was $\sim 27$ at.\%. In this study [9], the $\gamma_{\mathrm{N}}$ lattice expansion compared to the 304 SS substrate fcc $\gamma-(\mathrm{Fe}, \mathrm{Cr}, \mathrm{Ni})$ phase was about $9 \%$, which is quite close to the value $(\sim 10 \%)$ in our study.

Fig. 2 shows the topographical and cross-sectional SEM results for the plasma nitrided 316L SS specimen. The SEM image in Fig. 2(a) illustrates the uniform nature of the $\gamma_{N}$ layer. Based on the analysis of several SEM pictures, the nitrided layer thickness is found to be $\sim 6 \mu \mathrm{m}$. This value correlates quite well with that obtained from the AFM analysis (to be discussed below). The SEM image in Fig. 2(b) shows the change in surface morphology induced by the plasma nitriding. Careful analysis of these and many other images clearly reveal periodic arrays of lines on the nitrided surface indicating the presence of slip bands inside the grains. The strain resulting from high nitrogen contents is believed to responsible for the formation of the slip bands in the $\gamma_{\mathrm{N}}$ layer. This finding agrees quite well with an earlier study, in which 304 SS was plasma nitrided at $400{ }^{\circ} \mathrm{C}$ by a low-pressure plasma arc-source ion nitriding method [17]. This study concluded that a high slip band density can be observed on the nitrided surface when the strain resulting from nitrogen supersaturation is great enough to activate the primary $\{111\}$ slip system. Similar slip line patterns were also observed by an ion implantation study of $316 \mathrm{SS}$ at $400{ }^{\circ} \mathrm{C}$ with treatment conditions similar to those for low-energy, high-flux ones [18]. The formation of slip bands suggest plastic deformation of the grains, and this, in turn, implies important compressive stresses operating in the $\gamma_{\mathrm{N}}$ layer. Thus, lattice expansion (nearly $10 \%$ ) of a surface layer in coherence (lattice registry) with a substrate of the same fcc structure must provide a strong driving force for the plasticity observed in the $\gamma_{\mathrm{N}}$ layer.

The magnetic character of the $\gamma_{N}$ layer on 316L SS specimen was investigated by magnetic force microscopy and vibrating sample
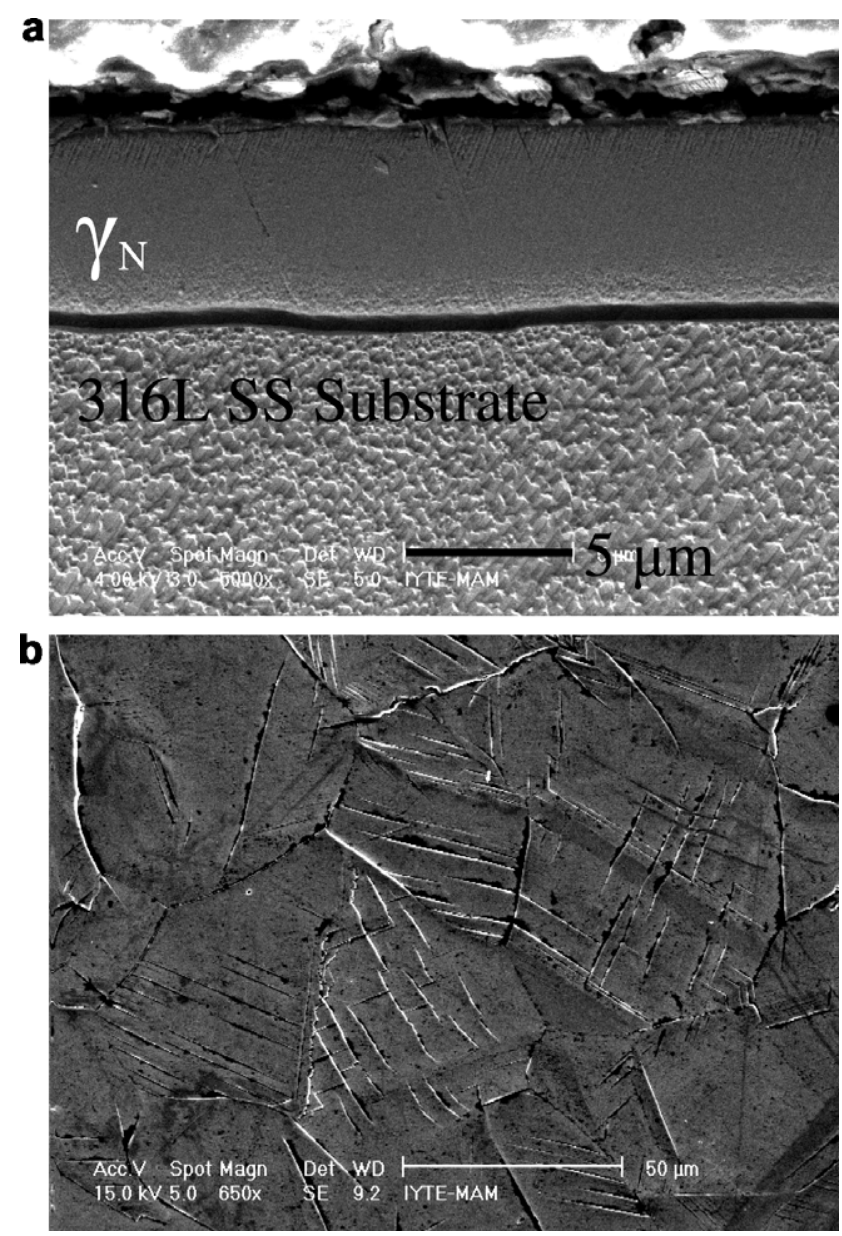

Fig. 2. (a) Cross-sectional SEM data for the plasma nitrided specimen. (b) SEM topographical image of the surface of the plasma nitrided specimen.

magnetometry. Figs. 3 and 4 display a series of MFM images taken both on the nitrided surface and on the nitrided cross-section. The dark and light bands in these images are characteristic signatures of the remnant magnetic domains present. The appearance of such stripe domain patterns is a clear indication of ferromagnetism in the $\gamma_{\mathrm{N}}$ layer. Also, a stripe domain structure is clear evidence for a significant out-of-plane magnetization component. The MFM images in Fig. 3 also indicate that the magnetic behaviour changes from one grain to another. The variation in the size and form of the magnetic domains from grain to grain may be attributed to the orientation of the individual grains and to different $\mathrm{N}$ contents and different amounts of lattice expansions in the different grains as indicated from the quantitative XRD data in Table 1 . The very fine nature of the domains is revealed by the MFM image in Fig. 3(b). According to this image, the domain size is estimated to be less than half a micron.

The topographical AFM image in Fig. 3(c) shows relatively rough surfaces with relief at grain boundaries and evidence of slippage within individual grains. The rough nature of the surface is also revealed by the observation of the grains in the SEM images (Fig. 2(b)). These effects can be attributed to the stresses induced in the $\gamma_{\mathrm{N}}$ layer due to larger lattice expansions evidenced by XRD. Roughening due to the nitriding on the substrate material based on the AFM image in Fig. 3(c) and a few others is found be $\sim 73 \mathrm{~nm}$. Note that the source of roughness here is not due to the sputtering of the surface since the nitriding process implemented here is basically a sputterless process.

Fig. 4 shows cross-sectional AFM and MFM images of the same regions along the $\gamma_{\mathrm{N}}$ layer. The AFM images indicate the extremely 
a

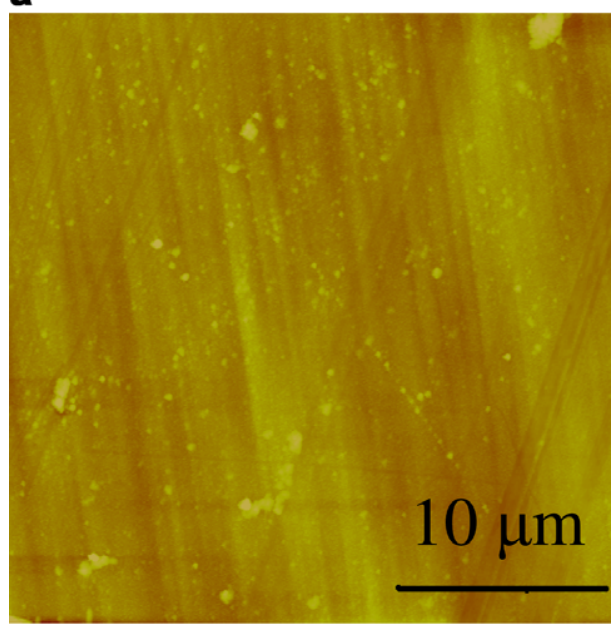

C

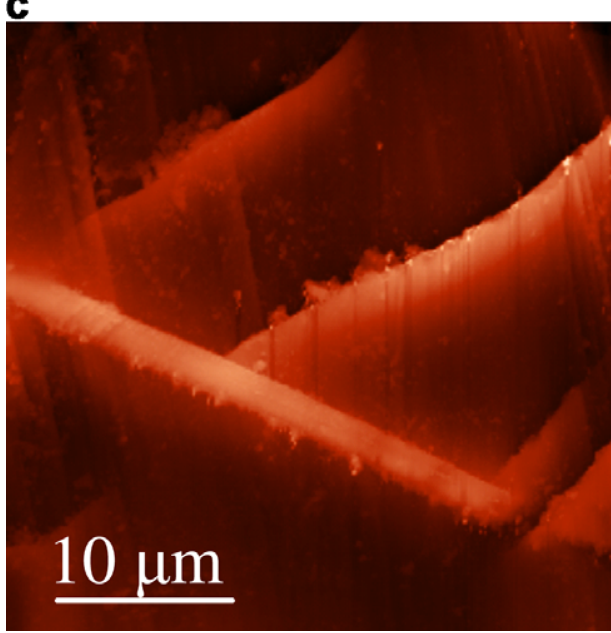

b

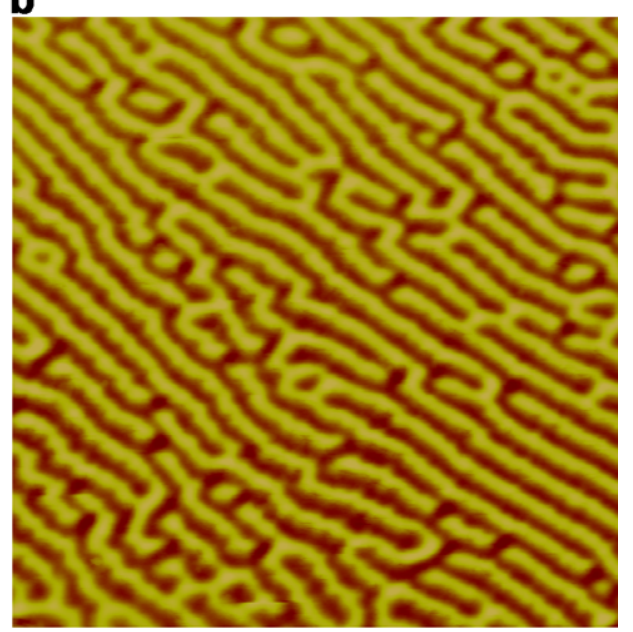

d

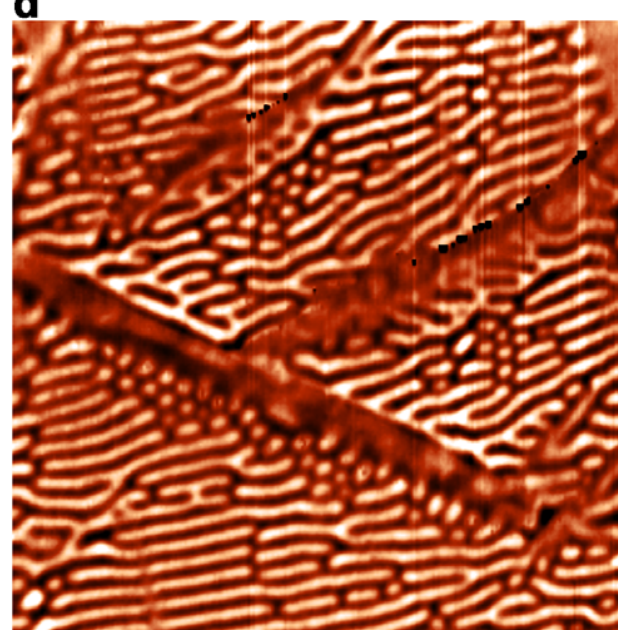

Fig. 3. A series of AFM and MFM images of the same regions on the plasma nitrided surface. (a) Atomic force image and (b) magnetic force image of the same area of the surface of the nitrided specimen. This is also the case for the images in (c) and (d).

a

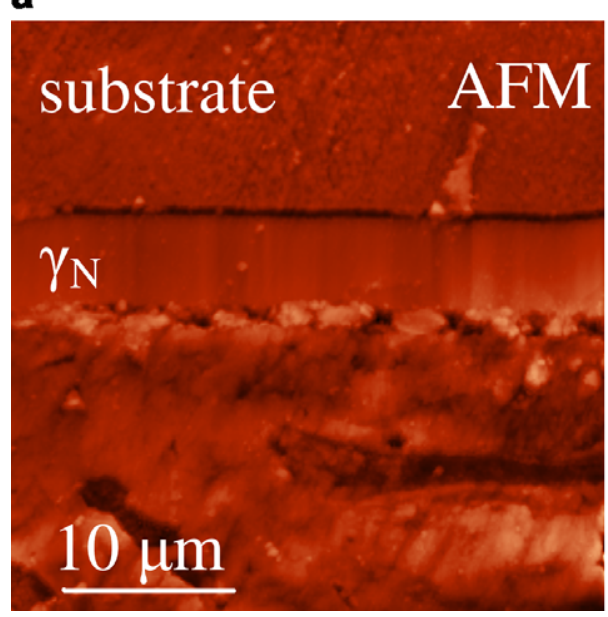

b

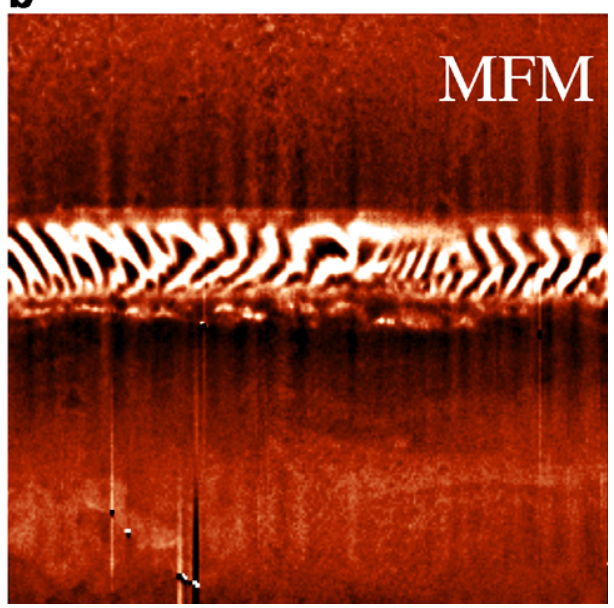

Fig. 4. Cross-sectional AFM and MFM images of the same regions. (a) Atomic force image and (b) magnetic force image of the same region as in (a).

uniform nature of the $\gamma_{\mathrm{N}}$ layer in a given grain. The average $\gamma_{\mathrm{N}}$ layer thickness, based on careful examination of several cross-sectional AFM images, is found to be $\sim 5.73 \mu \mathrm{m}$, which agrees reasonably well with that obtained from the cross-sectional SEM analysis.
Note also that the AFM images suggest a high acid etch resistance for the $\gamma_{\mathrm{N}}$ layer (nitrogen-rich region) compared to the 316L SS substrate. The cross-sectional MFM images in Fig. 4 illustrate the distribution of the magnetic domains throughout the nitrided 
layer. These images suggest that almost the entire $\gamma_{\mathrm{N}}$ layer is of ferromagnetic nature. The observation of the ferromagnetic region through almost the entire $\gamma_{\mathrm{N}}$ layer in this study is in contrast with previous research (via Mössbauer spectroscopy) related to the $\gamma_{\mathrm{N}}$ layer [9]. The MFM studies [11] of a plasma-immersion ion implanted 316 SS at $400{ }^{\circ} \mathrm{C}$ show that only the outer $80 \%$ of the $\gamma_{\mathrm{N}}$ layer is of ferromagnetic nature. According to this MFM study, no visible magnetic domains were present in the deepest $20 \%$ of the layer (i.e. this region is paramagnetic). This research suggested that the treated layer stops being ferromagnetic at a depth where the nitrogen concentration is approximately two thirds of its value at the surface. Furthermore, this study indicated that the high dislocation density observed in the interface region by TEM may be responsible for the change in magnetic properties. The Mössbauer study of low-energy, high-flux $\mathrm{N}$ implanted $304 \mathrm{SS}$ at $400{ }^{\circ} \mathrm{C}$, on the other hand, showed that the ferromagnetic region extends over less than half of the thickness of the $\gamma_{\mathrm{N}}$ layer. The differences observed between the studies in $[9,11]$ and the one in this study may be due to the incorporation of nitrogen into the materials by different processes. Fewell et al. [11] attributes this difference to the differently-shaped nitrogen concentration profiles.

Additional data related to the magnetic behaviour of the $\gamma_{N}$ layer on the 316L SS substrate material was obtained by vibrating sample magnetometry. The VSM measurements were performed to determine both the in-plane and out-of-plane hysteresis loops. Fig. 5 shows the experimental VSM results from the plasma nitrided 316L SS sample and an unnitrided 316L SS specimen with a similar geometry to that of the nitrided specimen. The hysteresis loops for the plasma nitrided sample demonstrate ferromagnetic type behaviour and suggest both out-of-plane and in-plane magnetization of the domain structure. The lack of saturation for the nitrided sample is due to the contribution of the non-magnetic (paramagnetic) signal to its VSM data. The substrate material has neither a loop structure nor saturation behaviour. The VSM data for the substrate material is consistent with its being paramagnetic at room temperature. Although the MFM images of the stripe domains suggest mainly out-of-plane magnetization for the $\gamma_{\mathrm{N}}$ layer, the VSM analysis results imply both out-of-plane and in-plane magnetization of the domain structure. From the VSM data, the coercive field is estimated to be $\sim 85$ Gauss. The characteristic shown by the hysteresis loop for the plasma nitrided specimen is similar to that of a softer ferromagnet such as soft iron.

The ferromagnetic ordering for the fcc high-N phase $\left(\gamma_{N}\right.$ phase) observed in this and earlier studies is supported by other studies in

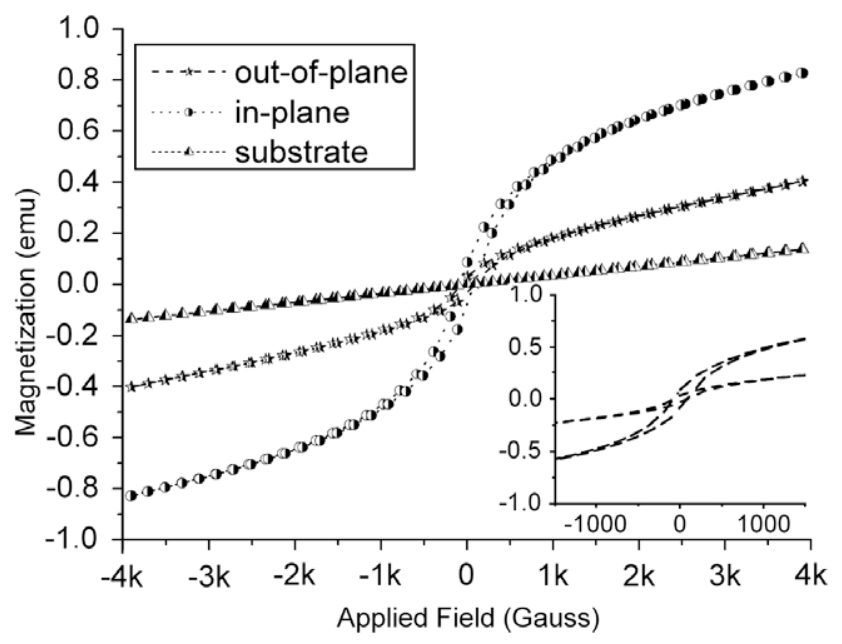

Fig. 5. VSM data for the plasma nitrided specimen as well as a 316L SS substrate alloy material. which hydrogen and carbon atoms are incorporated into the fcc lattice by different methods [19,20]. A high-pressure hydrogen incorporation study of 304 and 310 SS (using a SQUID technique) shows that both steels become ferromagnetic at high hydrogen concentrations. This study [19], in which hydrogenation of 304 and 310 samples were performed in a high-pressure cell at $350{ }^{\circ} \mathrm{C}$ for $24 \mathrm{~h}$ under pressures of up to $7 \mathrm{GPa}$, showed that the hydrogenation of both 304 and 310 SS steels resulted in a pure expanded fcc lattice. The conclusion of this study was that hydrogenation leads to lattice expansion i.e. the Fe-Fe distance is increased, which strongly influences the magnetic interactions. A quite recent study related to Fe nanoparticles trapped inside carbon nanotube films show that the fcc-Fe particles grown within graphitic nanotubes remain structurally stable and appear ferromagnetic at room temperature [20]. This study suggested that the ferromagnetism observed in the fcc-Fe is related to both lattice expansion (due to carbon incorporation) and charge transfer between iron and carbon. This study indicated less than 10 at.\% of carbon atoms are interstitially inside the Fe unit cells.

The results on the magnetic nature of $\gamma_{\mathrm{N}}$ (and $\gamma_{\mathrm{H}}$ and $\gamma_{\mathrm{C}}$ as just discussed) are consistent with the well-known concept that fcc-Fe can exist in two distinct magnetic states depending on the lattice constant (or atomic volume) of the Fe: a low moment, antiferromagnetic state at low volumes and a high moment, ferromagnetic state at high volumes [21]. The ferromagnetic nature of $\gamma_{N}\left(\gamma_{H}\right.$ and $\gamma_{C}$ ) can be attributed to the high volume, high moment, ferromagnetic, fcc-Fe state.

\section{Conclusions}

In this study, structural and magnetic behaviour of the $\gamma_{\mathrm{N}}$ layer formed on 316L SS substrate by a low-pressure RF plasma method was investigated. Combined X-ray diffraction, cross-sectional SEM, AFM and MFM, as well as VSM analyses provide strong evidence for the formation of the $\gamma_{\mathrm{N}}$ phase, $\left[\gamma_{\mathrm{N}}-(\mathrm{Fe}, \mathrm{Cr}, \mathrm{Ni})\right]$, with mainly ferromagnetic characteristics. The uniform nature of the $\gamma_{\mathrm{N}}$ layer is clearly demonstrated by the XRD, cross-sectional SEM and AFM analyses. Based on the AFM and SEM data, the thickness of the $\gamma_{\mathrm{N}}$ layer is found to be $\sim 6 \mu \mathrm{m}$. According to the MFM and VSM analyses, ferromagnetism in the $\gamma_{\mathrm{N}}$ layer is revealed by the observation of stripe domain structures and the hysteresis loops. The cross-sectional MFM results demonstrate the ferromagnetic $\gamma_{N}$ phase distributed across the plasma nitrided layer. The MFM images show variation in the size and form of the magnetic domains from one grain to another. This is attributed mainly to the orientation of the individual grains and different amounts of the lattice expansion in the different grains as indicated from the XRD data.

\section{Acknowledgments}

The authors would like to thank Michel Drouet of Universite de Poitiers for performing the plasma nitriding. We are also grateful to Associate Professor Salih Okur and graduate student Nilban Sonmez for their help with some MFM measurements. Financial support for this project was partially provided by Tubitak (National Science Foundation of Turkey) through grant TBAG-2444.

\section{References}

[1] Z.L. Zhang, T. Bell, Surf. Eng. 1 (1985) 131.

[2] K. Ichii, K. Fujimura, T. Takase, Technol. Reports Kansai Univ., Vol. 127, 1986, p. 134.

[3] D.L. Williamson, O. Ozturk, R. Wei, P.L. Wilbur, Surf. Coat. Technol. 65 (1994) 15.

[4] G.A. Collins, R. Hutchings, K.T. Short, J. Tendys, X. Li, M. Samandi, Surf. Coat. Technol. 74-75 (1995) 417. 
[5] S. Parascandola, R. Günzel, R. Grötzshel, E. Richter, W. Möller, Nucl. Instrum. Meth. Phys. Res. B 136-138 (1998) 1281.

[6] J.P. Riviere, P. Meheust, J.P. Villain, C. Templier, M. Cahoreu, G. Abrasonis, L Pranevicius, Surf. Coat. Technol. 158-159 (2002) 99.

[7] R. Wei, B. Shogrin, P.J. Wilbur, O. Ozturk, D.L. Williamson, I. Ivanov, E. Metin, J. Tribol. 116 (1994) 870.

[8] S. Mändl, B. Rauschenbach, J. Appl. Phys. 88 (2000) 3323.

[9] O. Öztürk, D.L. Williamson, J. Appl. Phys. 77 (1995) 3839.

[10] D.L. Williamson, P.J. Wilbur, F.R. Fickett, S. Parascandola, in: T. Bell, K. Akkamatsu (Eds.), Stainless Steel 2000 - Proceedings of an International Current Status Seminar on Thermochemical Surface Engineering of Stainless Steels, The Institute of Materials, London, 2001, p. 333.

[11] M.P. Fewell, D.R.G. Mitchell, J.M. Priest, K.T. Short, G.A. Collins, Surf. Coat Technol. 131 (2000) 300.
[12] L. Marot, A. Straboni, M. Drouet, Surf. Coat. Technol. 142-144 (2001) 384

[13] L. Marot, E. Le Bourhis, A. Straboni, Mater. Lett. 56 (2002) 76.

[14] A. Dias, M.S. Andrade, Appl. Surf. Sci. 161 (2000) 109.

[15] J.C. Jiang, I. Meletis, J. Appl. Phys. 88 (2000) 4026

[16] G. Abronis, J.P. Riviere, C. Templier, L. Pranevicius, N.P. Barradas, J. Appl. Phys. 97 (2005) 124906

[17] X. Xu, Z. Yu, L. Wang, J. Quiang, Z. Hei, Surf. Coat. Technol. 162 (2003) 242.

[18] S. Grigull, S. Parascandola, J. Appl. Phys. 88 (2000) 6925.

[19] M. Hoelzel, S.A. Danilkin, H. Ehrenberg, D.M. Toebbens, T.J. Udovic, H. Fuess, H. Wipf, Mater. Sci. Eng. A 384 (2004) 255.

[20] B. Wei, M. Shima, R. Pati, S.K. Nayak, D.J. Singh, R. Ma, Y. Li, Y. Bando, S. Nasu, P.M. Ajayan, Small 2 (2006) 804

[21] M. Uhl, M. Sandratskii, J. Kübler, Phys. Rev. B 50 (1994) 291. 